\section{Abordagem do Doente Difícil: O Exemplo de Zamora}

\section{Management of the Difficult Patient: The Example of Zamora}

Palavras-chave: Prestação de Cuidados de Saúde; Psiquiatria Comunitária; Reabilitação; Saúde Mental

Keywords: Community Psychiatry; Delivery of Health Care; Mental Health; Rehabilitation

A situação pandémica mundial agravou os desafios existentes na prática clínica diária. Foram particularmente evidentes as dificuldades na gestão da patologia psiquiátrica grave e dos 'doentes difíceis'. Como abordado no artigo "Doentes Difíceis: Uma Perspetiva dos Cuidados Terciários em Saúde Mental",' a necessidade de serviços especializados torna-se premente à luz da atual situação sanitária.

Diversos centros hospitalares têm encetado esforços no sentido da criação e reforço de equipas de intervenção comunitária, indo ao encontro das mais recentes recomendações da Organização Mundial de Saúde para os cuidados de saúde na área da Saúde Mental $^{2}$ e do Plano Nacional de Saúde Mental. ${ }^{3}$ Ambos reforçam que os serviços de saúde mental devem integrar-se nas estruturas da comunidade e trabalhar em complementaridade com os serviços de saúde primários.

O conceito de asilo psiquiátrico ou de isolamento da pessoa com doença mental está em claro desuso, tornando-se urgente a implementação de novos modelos de assistência a estas pessoas, modelos biopsicossociais, centrados na pessoa e no seu meio envolvente, descentralizando o enfoque na doença. ${ }^{4}$

\section{REFERÊNCIAS}

1. Carnot MJ, Gama Marques J. 'Doentes difíceis': uma perspectiva dos cuidados terciários em saúde mental. Acta Med Port. 2018;31:370-2.

2. World Health Organization. The World Health Report 2001: mental health: new understanding, new hope. Geneva: WHO; 2001.

3. Direção Geral da Saúde. Programa Nacional para a Saúde Mental 2017. [consultado 2020 nov 10]. Disponível em: https://www.dgs.pt/portal-da-
Tivemos a oportunidade de conhecer e estagiar num reconhecido exemplo de abordagem multidisciplinar estruturada - o Complexo Assistencial de Zamora, centro hospitalar que integra o serviço de saúde público da comunidade autónoma espanhola de Castela e Leão.

A atividade clínica do Serviço de Psiquiatria deste centro hospitalar centra-se de forma considerável em trabalho de assistência comunitária, correspondendo os cuidados hospitalares a uma minoria dos serviços prestados. Existe uma rede socio-sanitária em articulação permanente, que dispõe de uma larga gama de recursos humanos e materiais ligados quer ao hospital quer a entidades externas particulares.

Contactámos e colaborámos com as equipas multidisciplinares de Saúde Mental, constituídas por psiquiatras, enfermeiros, psicólogos e auxiliares de ação médica, que se deslocam semanalmente aos centros de saúde e aos domicílios dos doentes mais graves. Estas equipas, em estreita coordenação com assistentes sociais e outros técnicos de reabilitação social, prestam cuidados especializados à população de 'doentes difíceis' das 22 unidades básicas de saúde da província.

O modelo de Zamora faz-nos agora pensar que é imperioso dispor de mais destas equipas especializadas em Portugal, que possam assegurar o apoio domiciliário e adequar os cuidados, favorecendo a inclusão dos doentes na comunidade e aliviando a sobrecarga hospitalar. ${ }^{1,4}$ Numa altura de incerteza sanitária e de maior incapacidade de resposta hospitalar, torna-se essencial reinventar estratégias de intervenção comunitária.

\footnotetext{
Inês PINTO $\bigotimes^{* 1}$, Liliana MORENO*2

* Co-primeiros autores

1. Clínica 1. Centro Hospitalar Psiquiátrico de Lisboa. Lisboa. Portugal.

2. Departamento de Psiquiatria e Saúde Mental. Centro Hospitalar de Setúbal. Setúbal. Portugal.

Autor correspondente: Inês Pinto. inespinto@chpl.min-saude.pt

Recebido: 16 de novembro de 2020 - Aceite: 15 de dezembro de 2020 - Online issue published: 01 de fevereiro de 2021

Copyright @ Ordem dos Médicos 2021

https://doi.org/10.20344/amp.15330
}

estatistica-da-saude/diretorio-de-informacao/diretorio-de-informacao/ por-serie-883589-pdf.aspx?v=\%3d\%3dDwAAAB\%2bLCAAAAAAABAA rySzItzVUy81MsTU1MDAFAHzFEfkPAAAA.

4. Sevillano-Jiménez A, Ruano-García C. El tratamiento asertivo comunitario como modalidad de atención en salud mental. Rol de la enfermera especialista. Enferm Clin. 2019;29:388-90. 